\title{
QUALIDADE DE VIDA NO TRABALHO: CONTEXTO DE ATUAÇÃO PROFISSIONAL E CARREIRA DOCENTE
}

\author{
Rosane Ferreira Veiga \\ Universidade Federal de Pelotas, Pelotas, Rio Grande do Sul, Brasil \\ Mariângela da Rosa Afonso \\ Universidade Federal de Pelotas, Pelotas, Rio Grande do Sul, Brasil \\ Gelcemar Oliveira Farias \\ Universidade do Estado de Santa Catarina, Florianópolis, Santa Catarina, Brasil \\ Edilene Cunha Sinott \\ Universidade Federal de Pelotas, Pelotas, Rio Grande do Sul, Brasil \\ José Antonio Bicca Ribeiro \\ Universidade Federal de Pelotas, Pelotas, Rio Grande do Sul, Brasil
}

\begin{abstract}
Resumo
O estudo objetivou analisar os aspectos intervenientes da qualidade de vida de professores de Educação Física, considerando sua satisfação no ambiente de trabalho. Participaram 94 professores, vinculados à SMED de Pelotas. Os instrumentos foram o QVT-PEF e um questionário sócio demográfico. Os dados foram analisados no STATA 12.0 adotando a significância de 5\%. A maior prevalência de satisfação no trabalho foi obtida na dimensão da Oportunidade imediata para uso e desenvolvimento das capacidades humanas. Já a maior prevalência de insatisfação foi encontrada na dimensão da Remuneração e compensação. A satisfação no trabalho é uma dimensão importante na avaliação da qualidade de vida, mas aspectos relacionados à precarização do trabalho docente são fatores negativos deste contexto.
\end{abstract}

Palavras-chave: Qualidade de vida. Docentes. Satisfação no Emprego.

\section{Introdução}

A qualidade de vida (QV) de cada indivíduo é formada, em parte, pela qualidade de vida no trabalho. Sendo esta de extrema importância, tem sido estudada por diversos autores (BOTH et al., 2006; LEMOS et al., 2007; GATTI et al., 2008). Há então, uma necessidade de que as pessoas sintam-se satisfeitas com suas obrigações diárias para que possam produzir mais e melhor.

De acordo com Souza et al. (2003), há algumas décadas, a maior parte dos profissionais da educação tinham uma considerada valorização social e, com isso, gozavam de um relativo poder aquisitivo, um emprego seguro e uma importante valorização profissional. A partir das novas políticas educacionais, houve um desgaste da escola pública, gerando uma desvalorização crescente desses profissionais trazendo grandes consequências para as relações 
de trabalho. Seria importante rever as mudanças educacionais e suas possíveis inadequações com a realidade enfrentada por esses profissionais (SOUZA et al., 2003; GASPARINI et al., 2005).

A carreira docente é marcada por desafios que podem influenciar diretamente a identidade do professor, provocando mudanças em sua trajetória profissional que podem ir do encanto à frustração, pois o docente passa a viver um conflito com a carreira idealizada a partir de sua rotina diária (FOLLE; NASCIMENTO, 2008; FARIAS et al., 2008; LEMOS, 2009, MOREIRA et al. 2012).

Nahas (2010) ressalta que pesquisas recentes apontam para uma valorização dos fatores que envolvem o bem-estar e a importância de suprir as necessidades básicas para buscar equilíbrio entre o lado profissional e o pessoal. $\mathrm{O}$ autor ainda afirma que parâmetros socioambientais (moradia, assistência médica, condições de trabalho, remuneração, educação, opções de lazer, meio ambiente) e parâmetros individuais (a hereditariedade e o estilo de vida) podem influenciar a QV e a satisfação dos indivíduos em diferentes aspectos do seu cotidiano.

A satisfação pode ser considerada um estado de bem-estar ou de prazer que envolve a saúde física e mental. Ela resulta da realização de algo que se espera ou deseja, partindo de um único indivíduo ou de um grupo de pessoas, sendo resultado da necessidade. A satisfação no trabalho faz parte da cultura de uma instituição, e, a filosofia de uma empresa é capaz de estimular valores para o desenvolvimento de um modelo que tenha como objetivo melhorar a QV de seus membros. A insatisfação é gerada pelos elementos do ambiente de trabalho e a satisfação é consequência de aspectos relativos ao próprio trabalho (MARTINEZ; PARAGUAY, 2003).

Hoje o papel do professor estendeu-se para além da sala de aula, pois, afora ensinar, deve participar da gestão escolar, o que significa uma dedicação maior junto à comunidade. Ainda que o sucesso da educação esteja sujeito ao perfil do professor, esse, muitas vezes não recebe apoio das equipes pedagógicas, bem como da administração escolar e, dessa forma, não tem acesso aos recursos tecnológicos cada vez mais complexos, onde a remuneração recebida pelo trabalho fica aquém da responsabilidade e carga de trabalho realizada (BARRETO; LEHER, 2003; OLIVEIRA, 2003).

Considerando o exposto anteriormente, este estudo teve como objetivo analisar os aspectos intervenientes na QV dos professores de Educação Física da rede pública municipal de Pelotas/RS, considerando, sobretudo sua satisfação no ambiente de trabalho. Nesse sentido, acreditamos que mudanças no contexto educativo possam ser fomentadas, particularmente na compreensão das situações que envolvem o trabalho docente na rede municipal de ensino, contribuindo para uma maior satisfação e QV no trabalho.

\section{Método}

O estudo caracterizou-se como uma pesquisa descritiva de abordagem quantitativa (THOMAS; NELSON, 2002), na qual buscou-se analisar os professores de Educação Física quanto à sua QV no ambiente de trabalho.

Fizeram parte do estudo $94(79,7 \%)$ professores de Educação Física, vinculados à Secretaria Municipal de Educação e Desporto (SMED) da cidade de Pelotas/RS. Destes, 29,8\% dos docentes cumprem uma carga horária de trabalho de até 39 horas e 70,2\% cumprem uma carga horária de 40 horas ou mais.

Para a coleta de dados, utilizou-se como instrumento um questionário composto por perguntas fechadas. Esse instrumento foi estruturado em duas partes: a primeira destinada à coleta de informações referentes aos dados sócio demográficos dos professores investigados e a segunda, destinada às informações sobre a QV no trabalho docente, por meio da Escala de Avaliação da Qualidade de Vida no Trabalho Percebida por Professores de Educação Física 
do Ensino Fundamental e Médio (QVT-PEF), desenvolvido por Both et al. (2006), composta por oito dimensões quais sejam: remuneração e compensação; condições de trabalho; oportunidade imediata para o uso e desenvolvimento de capacidades humanas; oportunidade futura de crescimento e segurança; integração social na organização do trabalho; constitucionalismo na organização de trabalho; trabalho e espaço total de vida e relevância social da vida no trabalho.

Na classificação dos professores nos ciclos de desenvolvimento profissional, utilizou-se como referência Farias e Nascimento (2012), os quais compreendem a carreira a partir de cinco ciclos: Entrada na carreira (1a 4 anos de docência); consolidação (5 a 9 anos de docência); afirmação e diversificação na carreira (10 a 19 anos de docência); renovação (20 a 27 de docência); e maturidade (28 anos ou mais).

Cabe destacar que a coleta de dados ocorreu mediante a autorização da SMED sendo que após esta ação, os professores foram visitados em suas escolas, recebendo as informações necessárias e todos foram convidados a participar voluntariamente do estudo. A pesquisa foi submetida ao Comitê de Ética em Pesquisa da ESEF/UFPEL, sendo aprovado a partir do protocolo número 016/2011.

$\mathrm{Na}$ análise dos dados obtidos por meio das respostas dos professores no que se refere ao QVT-PEF, utilizou-se as equações de ponderação de Lemos (2007), agregando-se as respostas em três categorias, quais sejam: insatisfeitos, indecisos e satisfeitos. Os testes do Quiquadrado e do Exato de Fischer foram empregados para observar a existência de diferenças nas variáveis categóricas, a partir do programa estatístico STATA, versão 12.0, cujo nível de significância adotado foi $5 \%$.

\section{Resultados e discussão}

Os resultados mostraram que: grande parte dos professores contemplados pela pesquisa era do sexo feminino $(63,8 \%)$; possuíam curso de Pós-Graduação $(52,1 \%)$; tinham idade igual ou superior a 40 anos $(53,3 \%)$; trabalhavam somente em escolas da rede municipal de ensino (69,1\%); trabalhavam mais de 40 horas semanais; $73(77,7 \%)$ atuavam somente ministrando aulas e $(18,1 \%)$ encontravam-se na fase de entrada na carreira (Tabela 1$)$. 
Tabela 1. Caracterização do trabalho docente

\begin{tabular}{cccc}
\hline Variáveis & Categorias & $\mathbf{N}$ & $\mathbf{( \% )}$ \\
\hline \multirow{2}{*}{ Sexo } & Masculino & 34 & 36,2 \\
& Feminino & 60 & 63,8 \\
\hline \multirow{2}{*}{ Formação Profissional } & Graduação & 45 & 47,9 \\
& Pós-Graduação & 49 & 52,1 \\
\hline \multirow{2}{*}{ Idade } & Até 39 anos & 44 & 46,8 \\
& 40 anos ou mais & 50 & 53,2 \\
\hline \multirow{2}{*}{ Redes de Ensino } & Município & 65 & 69,1 \\
& Município e outras & 29 & 30,9 \\
\hline \multirow{2}{*}{ Carga horária } & Até 39h & 28 & 29,8 \\
& 40h ou mais & 66 & 70,2 \\
\hline \multirow{2}{*}{ Contexto de atuação } & Sala de aula & 73 & 77,7 \\
& Sala de aula e outros & 21 & 22,3 \\
\hline \multirow{2}{*}{ Ciclos de desenvolvimento profis- } & Entrada na Carreira & 17 & 18,1 \\
sional & Consolidação & 27 & 28,7 \\
& Afirmação & 27 & 28,7 \\
& Renovação & 15 & 16,0 \\
& Maturidade & 8 & 8,5 \\
\hline
\end{tabular}

Na Tabela 2, constam informações relacionadas à análise da QV dos professores que trabalham somente na rede municipal de Pelotas e aqueles que trabalham em mais de uma rede de ensino. Destaca-se as maiores prevalências de satisfação com o trabalho nas dimensões: "Oportunidade imediata para uso e desenvolvimento das capacidades humanas" (66,1\%); "Constitucionalismo na organização do trabalho $(67,7 \%)$ e Relevância social da vida no trabalho $(55,4 \%)$. Neste mesmo grupo, as dimensões com maior prevalência de insatisfação no ambiente de trabalho foram: "Remuneração e compensação" $(69,2 \%)$ e "Condições de trabalho" $(35,4 \%)$.

No que diz respeito à $\mathrm{QV}$ dos professores que trabalham em outras redes de ensino, além da municipal, as dimensões com maior prevalência de satisfação foram: "Oportunidade imediata para uso e desenvolvimento das capacidades humanas" $(89,7 \%)$ e "Constitucionalismo na organização do trabalho" $(69,0 \%)$. As dimensões que apresentaram a maior prevalência de insatisfação entre professores que trabalhavam em outras redes de ensino foram: "Remuneração e compensação" (69,0\%) e "Trabalho e espaço total de vida" $(27,7 \%)$.

É possível perceber, ainda, que as respostas dos professores se aproximam, sobretudo, quando considera-se aspectos relacionados à remuneração e compensação pelo trabalho ou às condições de trabalho em que são submetidos, sendo que consideram-se insatisfeitos quando se remete a tais aspectos. Desta forma, os professores demonstraram ter satisfação com questões relacionadas ao desenvolvimento das capacidades, à organização ou à relevância do trabalho desempenhado.

A intervenção profissional em um único contexto poderia assegurar uma vida mais digna e com melhores condições de tranquilidade e de lazer, todavia, não é raro observar que ocorre um desdobramento dos docentes em várias escolas ou mesmo outros campos de intervenção para a garantia de melhor remuneração (LAPO; BUENO, 2003; BOTH, 2011; VIEIRA et al., 2011). Este deslocamento enfrentando um ritmo frenético na vida pessoal e profissional é demarcado pelo pluriemprego, que se percebe na profissão professor. Não obstante, é comum encontrar e investigar docentes que atuam em mais de uma rede de ensino, ou mesmo em outros contextos laborais. 
A atuação profissional, além do vínculo com a SMED pode caracterizar o pluriemprego, considerado comum na profissão docente. Caracteriza-se o pluriemprego por jornada dupla ou tripla de trabalho, bem como pela atuação em locais diferentes. A ansiedade gerada pelos baixos salários e as dificuldades financeiras constantes, podem acarretar a necessidade de atuação em locais e redes diversas, trazendo muitas vezes dificuldades em realizar as refeições entre uma jornada e outra, (NAHAS; BARROS; FRANCALACI, 2000; BOTH, 2011) sendo que de acordo com Cezar-Vaz (2015) uma das questões que se torna estressante no ambiente de trabalho do professor é renda salarial.

Com relação aos docentes que trabalham somente na rede municipal de Pelotas, esses demonstraram satisfação nas dimensões Oportunidade futura de crescimento e segurança $(43,1 \%)$ e Trabalho e espaço total da vida $(36,9 \%)$. Na dimensão Integração social na organização do trabalho, os professores que trabalham no município e outros locais $(55,2 \%)$ mostraram-se satisfeitos.

No que tange à dimensão das Condições de trabalho, pode-se observar igualdade nos percentuais de insatisfação e indecisão $(35,4 \%)$ dos professores atuantes na rede municipal de Pelotas, bem como insatisfação e indecisão $(34,5 \%)$ daqueles professores que atuam em outras redes de ensino. Além disso, os professores que atuam na rede municipal de Pelotas estão indecisos no que se refere à dimensão da Oportunidade futura de crescimento e segurança $(44,8 \%)$. Os professores que atuam também em outras redes ou contextos estão indecisos na dimensão da Integração social na organização do trabalho $(46,1 \%)$.

$\mathrm{O}$ ambiente hostil onde o professor atua (considerando espaço físico, relacionamentos, culturas locais, etc.) e as possibilidades de avanço na carreira são fatores que demarcam a trajetória docente, haja vista que a qualificação profissional deve ocorrer tanto no sentido horizontal, como no sentido vertical. O que se declara em alguns contextos é a falta de vagas que permita o avanço na carreira, bem como a falta de verba para a ampliação e revitalização das escolas.

Constatou-se que 30,9\% dos professores investigados trabalham em outras redes de ensino, o que não é um percentual expressivo, mas nesse caso é importante ponderar que mesmo os professores que trabalham somente em uma rede têm, muitas vezes, dupla ou tripla jornada em busca de uma remuneração condizente com as suas necessidades. 
Tabela 2. Qualidade de vida no trabalho docente e redes de atuação

\begin{tabular}{|c|c|c|c|c|}
\hline \multirow[b]{2}{*}{ Redes de Atuação } & \multicolumn{3}{|c|}{ Qualidade de Vida no Trabalho Docente } & \multirow[b]{2}{*}{ p-valor } \\
\hline & $\begin{array}{c}\text { Insatisfeito } \\
\text { n }(\%)\end{array}$ & $\begin{array}{c}\text { Indeciso } \\
\text { n (\%) }\end{array}$ & $\begin{array}{l}\text { Satisfeito } \\
\text { n }(\%)\end{array}$ & \\
\hline \multicolumn{5}{|c|}{ Remuneração e compensação } \\
\hline Municipal & $45(69,2 \%)$ & $17(26,1 \%)$ & $3(4,6 \%)$ & \multirow{2}{*}{$0,689 *$} \\
\hline Municipal e outras & $20(69,0 \%)$ & $9(31,0 \%)$ & $0(0,0 \%)$ & \\
\hline \multicolumn{5}{|c|}{ Condições de trabalho } \\
\hline Municipal & $23(35,4 \%)$ & $23(35,4 \%)$ & $19(29,2 \%)$ & \multirow{2}{*}{$1,000 * *$} \\
\hline Municipal e outras & $10(34,5 \%)$ & $10(34,5 \%)$ & $9(31,0 \%)$ & \\
\hline \multicolumn{5}{|c|}{ Oportunidade imediata para uso e desenvolvimento das capacidades humanas } \\
\hline Municipal & $4(6,1 \%)$ & $18(27,7 \%)$ & $43(66,1 \%)$ & \multirow[b]{2}{*}{$0,054 * *$} \\
\hline Municipal e outras & $0(0,0 \%)$ & $3(10,3 \%)$ & $26(89,7 \%)$ & \\
\hline \multicolumn{5}{|c|}{ Oportunidade futura de crescimento e segurança } \\
\hline Municipal & $14(21,5 \%)$ & $23(35,4 \%)$ & $28(43,1 \%)$ & \multirow{2}{*}{$0,574 *$} \\
\hline Municipal e outras & $4(13,8 \%)$ & $13(44,8 \%)$ & $12(41,4 \%)$ & \\
\hline \multicolumn{5}{|c|}{ Integração social na organização do trabalho } \\
\hline Municipal & $8(12,3 \%)$ & $30(46,1 \%)$ & $27(41,5 \%)$ & \multirow[b]{2}{*}{$0,465 * *$} \\
\hline Municipal e outras & $3(10,3 \%)$ & $10(34,5 \%)$ & $16(55,2 \%)$ & \\
\hline \multicolumn{5}{|c|}{ Constitucionalismo na organização do trabalho } \\
\hline Municipal & $3(4,6 \%)$ & $18(27,7 \%)$ & $44(67,7 \%)$ & \multirow{2}{*}{$0,757 * *$} \\
\hline Municipal e outras & $0(0,0 \%)$ & $9(31,0 \%)$ & $20(69,0 \%)$ & \\
\hline \multicolumn{5}{|c|}{ Trabalho e espaço total de vida } \\
\hline Municipal & $18(27,7 \%)^{3}$ & $23(35,4 \%)$ & $24(36,9 \%)$ & \multirow{2}{*}{$0,135 *$} \\
\hline Municipal e outras & $13(44,8 \%)$ & $5(17,2 \%)$ & $11(37,9 \%)$ & \\
\hline \multicolumn{5}{|c|}{ Relevância social da vida no trabalho } \\
\hline Municipal & $2(3,1 \%)$ & $27(41,5 \%)$ & $36(55,4 \%)$ & \multirow{2}{*}{$0,370 * *$} \\
\hline Municipal e outras & $0(0,0 \%)$ & $9(31,0 \%)$ & $20(69,0 \%)$ & \\
\hline \multicolumn{5}{|c|}{ Geral da Qualidade de vida no trabalho } \\
\hline Municipal & $7(10,8 \%)$ & $30(46,1 \%)$ & $28(43,1 \%)$ & \multirow{2}{*}{$0,897 * *$} \\
\hline Municipal e outras & $2(6,9 \%)$ & $14(48,3 \%)$ & $13(44,8 \%)$ & \\
\hline
\end{tabular}

Na avaliação da variável carga horária (Tabela 3) em relação às dimensões que se referem à QV no trabalho docente, os dados demonstraram que os professores com carga horária de até 39 horas apresentaram níveis de satisfação nas dimensões Oportunidade imediata para o uso e Desenvolvimento das capacidades humanas $(64,3 \%)$, Constitucionalismo na organização do trabalho $(67,9 \%)$ e Trabalho e espaço total da vida (46,4\%). Já os professores que trabalham mais de 40 horas manifestaram satisfação nas dimensões Oportunidade imediata para o uso e Desenvolvimento das capacidades humanas $(77,2 \%)$, Oportunidade futura de crescimento e segurança (42,4\%), Integração social na organização do trabalho $(50,0 \%)$, Constitucionalismo na organização do trabalho $(68,2 \%)$ e Relevância social da vida no trabalho $(66,7 \%)$.

Sinaliza-se que, tanto os professores que trabalham até 39 horas $(71,4 \%)$ como os professores que trabalham mais de 40 horas $(68,2 \%)$ apresentaram insatisfação em relação à dimensão remuneração e compensação. Entretanto, os professores com maior e menor carga horária de trabalho apresentaram, respectivamente, uma maior prevalência de satisfação nas 
dimensões: "Oportunidade imediata para uso e desenvolvimento das capacidades humanas (77,3\% e 64,3\%)", "Constitucionalismo na organização do trabalho" (68,2\% e 67,9\%).

Um dado relevante, no estudo, é de que os professores que atuam até 39 horas manifestaram insatisfação apenas na dimensão Remuneração e compensação e, por outro lado, tais professores estão indecisos quanto às dimensões: Condições de trabalho e Oportunidade futura de crescimento e segurança $(46,4 \%)$, e, Relevância social da vida no trabalho $(53,6 \%)$. O que pode parecer como discrepante esta informação, pode realmente ser uma situação plausível do governo local, pois como se vislumbram em estudos com referência a questão salarial dos docentes, sempre é um ponto de extrema negatividade. Na literatura consultada, Rocha (2012) declara que os resultados do seu estudo indicam a satisfação dos professores com o salário recebido. Um fator que pode justificar este dado se refere à dimensão e aos recursos financeiros de cada município, pois de acordo com o seu plano de governo pode influenciar diretamente no pagamento do servidor. Em estudo realizado com professores de Educação Física, Moreira et al. (2012) como em demais investigações, os índices de insatisfação com a remuneração são superiores à satisfação da categoria profissional.

No computo da avaliação geral da QV no trabalho dos docentes em relação à carga horária (Tabela 3), os professores que trabalham até 39 horas apresentaram-se indecisos $(50,0 \%)$, assim como os professores que trabalham mais de 40 horas $(45,4 \%)$. É sabido que a sobrecarga de trabalho pode promover a oscilação entre a qualidade de ensino e o sustento pessoal, que permite, de certa forma um descontentamento do professor com a sua opção de escolha profissional e pela sua carreira. Um dos fatores capazes de interferir negativamente na QV dos trabalhadores diz respeito justamente ao aumento da carga horária de trabalho. A vida moderna tem causado aos professores de Educação Física uma precária QV, já que, entre outras funções, eles possuem uma carga horária elevada de trabalho para corresponder às necessidades básicas de uma vida digna, para si e para sua família, extrapolando, dessa forma, as condições ideais de QV, trazendo influência para sua saúde física e mental (FUESS; LORENZ, 2003; SOUZA, 2003; GASPARINI, 2005; NAHAS, 2010; MOREIRA et al., 2012).

Ressalta-se que níveis de insatisfação foram detectados em professores que trabalham mais de 40 horas, na dimensão Remuneração e compensação e também na dimensão referente às Condições de trabalho e Espaço total da vida. Essa última requer equilíbrio entre o trabalho e o lazer e, diante dos resultados encontrados, constata-se que nem sempre isso ocorre. Devido à insatisfação com a remuneração alcançada, os professores estão procurando outras formas de aumentar sua renda familiar envolvendo-se em outras atividades. Outros estudos realizados com professores (PETROSKI, 2005; LEMOS et al., 2007; BOTH et al., 2008) encontraram resultados semelhantes, sendo a remuneração o fator principal de descontentamento por parte dos profissionais investigados.

É importante destacar que o docente extrapola seu tempo de lazer em função da sua carga horária intensa. Isso acontece devido à necessidade de obtenção de maiores ganhos mensais, prejudicando, muitas vezes, sua qualidade de vida. As cargas horárias elevadas dos professores, das mais diversas áreas do conhecimento, são investigadas, pois podem afetar a QV no trabalho docente, uma vez que as jornadas de trabalho chegam, muitas vezes, a ocupar três turnos, com pequenos intervalos e a exigência de atenção e concentração para dar conta do trabalho diário (VASCONCELOS, 2001; LAPO; BUENO, 2003; GRILLO; VIEIRA et al., 2011). 
Tabela 3. Qualidade de vida no trabalho docente e carga horária

\begin{tabular}{|c|c|c|c|c|}
\hline \multirow[b]{2}{*}{ Carga Horária } & \multicolumn{3}{|c|}{ Qualidade de Vida no Trabalho Docente } & \multirow[b]{2}{*}{ p-valor } \\
\hline & $\begin{array}{c}\text { Insatisfeito } \\
(\%)\end{array}$ & $\begin{array}{c}\text { Indeciso } \\
(\%)\end{array}$ & $\begin{array}{l}\text { Satisfeito } \\
(\%)\end{array}$ & \\
\hline \multicolumn{5}{|c|}{ Remuneração e compensação } \\
\hline Até 39 horas & $20(71,4 \%)$ & $8(28,6 \%)$ & $0(0,0 \%)$ & \multirow{2}{*}{$0,755^{*}$} \\
\hline Mais de 40 horas & $45(68,2 \%)$ & $18(27,3 \%)$ & $3(4,5 \%)$ & \\
\hline \multicolumn{5}{|c|}{ Condições de trabalho } \\
\hline Até 39 horas & $8(28,6 \%)$ & $13(46,4 \%)$ & $7(25,0 \%)$ & \multirow{2}{*}{$0,325 * *$} \\
\hline Mais de 40 horas & $25(37,9 \%)$ & $20(30,3 \%)$ & $21(31,8 \%)$ & \\
\hline \multicolumn{5}{|c|}{ Oportunidade imediata para uso e desenvolvimento das capacidades humanas } \\
\hline Até 39 horas & $2(7,1 \%)$ & $8(28,6 \%)$ & $18(64,3 \%)$ & \multirow{2}{*}{$0,295 *$} \\
\hline Mais de 40 horas & $2(3,0 \%)$ & $13(19,7 \%)$ & $51(77,3 \%)$ & \\
\hline \multicolumn{5}{|c|}{ Oportunidade futura de crescimento e segurança } \\
\hline Até 39 horas & $3(10,7 \%)$ & $13(46,4 \%)$ & $12(42,9 \%)$ & \multirow{2}{*}{$0,338 * *$} \\
\hline Mais de 40 horas & $15(22,7 \%)$ & $23(34,8 \%)$ & $28(42,4 \%)$ & \\
\hline \multicolumn{5}{|c|}{ Integração social na organização do trabalho } \\
\hline Até 39 horas & $5(17,9 \%)$ & $13(46,4 \%)$ & $10(35,7 \%)$ & \multirow{2}{*}{$0,315 * *$} \\
\hline Mais de 40 horas & $6(9,1 \%)$ & $27(40,9 \%)$ & $33(50,0 \%)$ & \\
\hline \multicolumn{5}{|c|}{ Constitucionalismo na organização do trabalho } \\
\hline Até 39 horas & $2(7,1 \%)$ & $7(25,0 \%)$ & $19(67,9 \%)$ & \multirow{2}{*}{$0,341 * *$} \\
\hline Mais de 40 horas & $1(1,5 \%)$ & $20(30,3 \%)$ & $45(68,2 \%)$ & \\
\hline \multicolumn{5}{|c|}{ Trabalho e espaço total de vida } \\
\hline Até 39 horas & $8(28,6 \%)$ & $7(25,0 \%)$ & $13(46,4 \%)$ & \multirow{2}{*}{$0,485^{*}$} \\
\hline Mais de 40 horas & $23(34,8 \%)$ & $21(31,8 \%)$ & $22(33,3 \%)$ & \\
\hline \multicolumn{5}{|c|}{ Relevância social da vida no trabalho } \\
\hline Até 39 horas & $1(3,6 \%)$ & $15(53,6 \%)$ & $12(42,8 \%)$ & \multirow{2}{*}{$0,063 * *$} \\
\hline Mais de 40 horas & $1(1,5 \%)$ & $21(31,8 \%)$ & $44(66,7 \%)$ & \\
\hline \multicolumn{5}{|c|}{ Geral da Qualidade de vida no trabalho } \\
\hline Até 39 horas & $3(10,7 \%)$ & $14(50,0 \%)$ & $11(39,3 \%)$ & \multirow{2}{*}{$0,800 * *$} \\
\hline Mais de 40 horas & $6(9,2 \%)$ & $30(45,4 \%)$ & $30(45,4 \%)$ & \\
\hline \multicolumn{5}{|c|}{ *p estimado pelo teste Exato de Fisher; ${ }^{* *}$ p estimado pelo teste do Qui-quadrado } \\
\hline \multirow{2}{*}{\multicolumn{5}{|c|}{$\begin{array}{l}\text { O avanço na carreira proporciona maior amadurecimento para assumir novas funções } \\
\text { na escola, assim como inúmeras chances para encontrar uma posição estável no sistema edu- } \\
\text { cativo (LEMOS, 2007). Com o avanço na carreira os docentes buscam a sua estabilidade pro- } \\
\text { fissional, além de consolidarem as competências que desenvolveram ao longo da sua carreira } \\
\text { (FARIAS; NASCIMENTO, 2012), por outro lado, alguns docentes ainda mantêm-se receosos } \\
\text { frente à evolução dos alunos e a resistência às mudanças decorrentes das políticas educacio- } \\
\text { nais. }\end{array}$}} \\
\hline & & & & \\
\hline $\begin{array}{l}\text { Na avaliação da v } \\
\text { cão às dimensões que com }\end{array}$ & $\begin{array}{l}\text { iclos de desenve } \\
\text { QV no trabalho }\end{array}$ & $\begin{array}{l}\text { vimento profi } \\
\text { os dados den }\end{array}$ & $\begin{array}{l}\text { sional (Tabela } \\
\text { onstraram que }\end{array}$ & $\begin{array}{l}\text {, em rela- } \\
\text { dimensão }\end{array}$ \\
\hline $\begin{array}{l}\text { Remuneração e compensaç } \\
\text { qual apresenta maiores índ } \\
\text { fessores mantêm-se insatis } \\
\text { nos ciclos de entrada (5) } \\
(60,0 \%) \text { os níveis de satisf }\end{array}$ & $\begin{array}{l}\text { la dentre as diı } \\
\text { atisfação, não } \\
\text { mentam os nív } \\
\text { nsolidação }(81 \\
\text { nenores em rel }\end{array}$ & $\begin{array}{l}\text { nsões que co } \\
\text { stante, com } \\
\text { de insatisfa } \\
\% \text {, diversif }\end{array}$ & $\begin{array}{l}\text { apõem a QV } \\
\text { avanço na ca } \\
\text { lo. Assim, no } \\
\text { ação }(74,1 \%\end{array}$ & $\begin{array}{l}\text { trabalho a } \\
\text { ra os pro- } \\
\text { adamente, } \\
\text { enovação }\end{array}$ \\
\hline
\end{tabular}


No que tange à dimensão condições de trabalho, níveis de satisfação foram observados em professores dos ciclos de consolidação (40,7\%), indecisão nos ciclos de entrada $(52,9 \%)$ e maturidade $(50,0 \%)$ e insatisfação no ciclo de diversificação $(44,4 \%)$, enquanto no ciclo de renovação ocorreu um equilíbrio entre indecisão e satisfação (40,0\%). Segundo Folle et al. (2008), com o avançar da carreira, os docentes tendem a demonstrar maior insatisfação com as condições de trabalho vindo ao encontro dos resultados encontrados neste estudo, no qual verificou-se satisfação apenas no ciclo de consolidação e, mesmo não se encontrando índices de insatisfação expressivos, encontrou-se indecisão na maioria dos ciclos.

Evidentemente, os professores com o decorrer da trajetória profissional necessitam de melhores condições de trabalho para garantir a qualidade de ensino dos discentes, melhoria da sua prática pedagógica e condição pessoal. Os estudiosos sobre os ciclos de vida profissional, tal como Huberman (2000) estabelece que os docentes em tempos avançados na carreira tendem a deter a suas preocupações mais centradas nas questões pessoais, sendo que estar com idade avançada e não ter boas condições resulta em insatisfação.

No que se refere à dimensão Oportunidade imediata para uso e Desenvolvimento das capacidades humanas, percebeu-se uma associação estatisticamente significativa $(p=0,035)$ entre os números de satisfeitos, insatisfeitos e indecisos, com as fases de desenvolvimento profissional, existindo uma tendência de os docentes insatisfeitos estarem nas fases de entrada na carreira e consolidação. Resultados semelhantes aos encontrados nos estudos de Petroski (2005); Lemos et al. (2007) e Both (2008), Moreira et al. (2012), nos quais prevalece a satisfação pelos resultados obtidos, auto realização em relação ao trabalho realizado, sendo capaz de comprometer sua saúde física e mental vindo a intervir em seu comportamento profissional e pessoal (OLIVEIRA, 2005).

Quanto à dimensão integração social na organização no trabalho os professores de Educação Física nos anos iniciais da carreira, respectivamente nos ciclos de entrada $(47,0 \%)$ e consolidação $(55,6 \%)$ estão satisfeitos com a QV no trabalho. Já os docentes com maior experiência na profissão, situados nos ciclos de diversificação $(63,0 \%)$ e renovação $(40,0 \%)$ se encontram indecisos.

Na dimensão Trabalho e espaço total da vida, que revela a relação de equilíbrio entre a dedicação pessoal com a vida profissional, os professores do ciclo de entrada $(52,9 \%)$, consolidação $(37,0 \%)$ e renovação $(40,0 \%)$ encontram-se mais insatisfeitos. Resultados semelhantes foram detectados no estudo de Both, Nascimento e Borgatto (2008), quando a maioria dos docentes revelou insatisfação com a referida dimensão.

Quanto à dimensão Relevância social da vida no trabalho, encontrou-se índices de satisfação nos ciclos de consolidação $(59,3 \%)$, diversificação $(63,0 \%)$, renovação $(73,3 \%)$ e maturidade $(62,5 \%)$, enquanto que os docentes do ciclo de entrada $(52,9 \%)$ na carreira manifestaram indecisão.

$\mathrm{Na}$ avaliação geral da dimensão que compõem a QV no trabalho e os ciclos da carreira, pode-se perceber que percentuais de insatisfação e satisfação se conjugam no decorrer da intervenção. Assim, aqueles docentes que se encontram nos ciclos de entrada $(47,1 \%)$ e renovação $(60,0 \%)$ estão satisfeitos, enquanto que os professores pertencentes ao ciclo de diversificação $(59,3 \%)$ e maturidade $(75,0 \%)$ encontravam-se indecisos. Sendo assim, ocorreu entre os docentes do ciclo de consolidação $(44,4 \%)$ o equilíbrio entre indecisão e satisfação.

A carreira docente é permeada por distintas situações que possibilitam o avançar e o recuo das ações mediadas pelos docentes, podendo ocorrer diferenciadas situações que possibilitam a aquisição de crenças, expectativas e perspectivas que se constroem e se desconstroem no decorrer da intervenção profissional (FARIAS, 2010; FARIAS; NASCIMENTO, 2012). Assim, é legitimo que políticas educacionais de formação continuada devam ser ofertadas aos docentes, no sentido de propor estratégias para o enfrentamento das possíveis dificuldades oriundas do ambiente de trabalho. 
Tabela 4. Qualidade de vida no trabalho docente e ciclos de desenvolvimento

\begin{tabular}{|c|c|c|c|c|}
\hline \multirow[b]{2}{*}{ Ciclos de Docência } & \multicolumn{3}{|c|}{ Qualidade de Vida no Trabalho Docente } & \multirow[b]{2}{*}{ p-valor } \\
\hline & $\begin{array}{l}\text { Insatisfeito } \\
(\%)\end{array}$ & $\begin{array}{l}\text { Indeciso } \\
(\%)\end{array}$ & $\begin{array}{l}\text { Satisfeito } \\
(\%)\end{array}$ & \\
\hline \multicolumn{5}{|c|}{ Remuneração e compensação } \\
\hline Entrada & $9(52,9 \%)$ & $7(41,2 \%)$ & $1(5,9 \%)$ & \\
\hline Consolidação & $22(81,5 \%)$ & $3(11,1 \%)$ & $2(7,4 \%)$ & \\
\hline Diversificação & $20(74,1 \%)$ & $7(25,9 \%)$ & $0(0,0 \%)$ & $0,609 *$ \\
\hline Renovação & $9(60,0 \%)$ & $6(40,0 \%)$ & $0(0,0 \%)$ & \\
\hline Maturidade & $5(62,5 \%)$ & $3(37,5 \%)$ & $0(0,0 \%)$ & \\
\hline \multicolumn{5}{|c|}{ Condições de trabalho } \\
\hline Entrada & $5(29,4 \%)$ & $9(52,9 \%)$ & $3(17,7 \%)$ & \\
\hline Consolidação & $10(37,0 \%)$ & $6(22,2 \%)$ & $11(40,7 \%)$ & \\
\hline Diversificação & $12(44,4 \%)$ & $8(29,6 \%)$ & $7(25,9 \%)$ & $0,936^{*}$ \\
\hline Renovação & $3(20,0 \%)$ & $6(40,0 \%)$ & $6(40,0 \%)$ & \\
\hline Maturidade & $3(37,5 \%)$ & $4(50,0 \%)$ & $1(12,5 \%)$ & \\
\hline \multicolumn{5}{|c|}{ Oportunidade imediata para uso e desenvolvimento das capacidades humanas } \\
\hline Entrada & $2(11,8 \%)$ & $4(23,5 \%)$ & $11(64,7 \%)$ & \\
\hline Consolidação & $2(7,4 \%)$ & $8(29,6 \%)$ & $17(63,0 \%)$ & \\
\hline Diversificação & $0(0,0 \%)$ & $4(14,8 \%)$ & $23(85,2 \%)$ & $0,035 *$ \\
\hline Renovação & $0(0,0 \%)$ & $4(26,7 \%)$ & $11(73,3 \%)$ & \\
\hline Maturidade & $0(0,0 \%)$ & $1(12,5 \%)$ & $7(87,5 \%)$ & \\
\hline \multicolumn{5}{|c|}{ Oportunidade futura de crescimento e segurança } \\
\hline Entrada & $3(17,6 \%)$ & $6(35,3 \%)$ & $8(47,1 \%)$ & \\
\hline Consolidação & $4(14,8 \%)$ & $11(40,7 \%)$ & $12(44,4 \%)$ & \\
\hline Diversificação & $6(22,2 \%)$ & $13(48,1 \%)$ & $8(29,6 \%)$ & $0,666 *$ \\
\hline Renovação & $2(13,3 \%)$ & $4(26,7 \%)$ & $9(60,0 \%)$ & \\
\hline Maturidade & $3(37,5 \%)$ & $2(25,0 \%)$ & $3(37,5 \%)$ & \\
\hline \multicolumn{5}{|c|}{ Integração social na organização do trabalho } \\
\hline Entrada & $3(17,6 \%)$ & $6(35,3 \%)$ & $8(47,1 \%)$ & \\
\hline Consolidação & $3(11,1 \%)$ & $9(33,3 \%)$ & $15(55,6 \%)$ & \\
\hline Diversificação & $1(3,7 \%)$ & $17(63,0 \%)$ & $9(33,3 \%)$ & $0,621 *$ \\
\hline Renovação & $1(6,7 \%)$ & $6(40,0 \%)$ & $8(53,3 \%)$ & \\
\hline Maturidade & $3(37,5 \%)$ & $2(25,0 \%)$ & $3(37,5 \%)$ & \\
\hline \multicolumn{5}{|c|}{ Constitucionalismo na organização do trabalho } \\
\hline Entrada & $2(11,7 \%)$ & $2(11,8 \%)$ & $13(76,5 \%)$ & \\
\hline Consolidação & $1(3,7 \%)$ & $6(22,2 \%)$ & $20(74,1 \%)$ & \\
\hline Diversificação & $0(0,0 \%)$ & $9(33,3 \%)$ & $18(66,7 \%)$ & $0,453 *$ \\
\hline Renovação & $0(0,0 \%)$ & $5(33,3 \%)$ & $10(66,7 \%)$ & \\
\hline Maturidade & $0(0,0 \%)$ & $5(62,5 \%)$ & $3(37,5 \%)$ & \\
\hline \multicolumn{5}{|c|}{ Trabalho e espaço total de vida } \\
\hline Entrada & $9(52,9 \%)$ & $2(11,8 \%)$ & $6(35,3 \%)$ & \\
\hline Consolidação & $10(37,0 \%)$ & $8(29,6 \%)$ & $9(33,3 \%)$ & \\
\hline Diversificação & $5(18,5 \%)$ & $7(25,9 \%)$ & $15(55,6 \%)$ & $0,388 *$ \\
\hline Renovação & $6(40,0 \%)$ & $6(40,0 \%)$ & $3(20,0 \%)$ & \\
\hline Maturidade & $1(12,5 \%)$ & $5(62,5 \%)$ & $2(25,0 \%)$ & \\
\hline \multicolumn{5}{|c|}{ Relevância social da vida no trabalho } \\
\hline Entrada & $1(5,9 \%)$ & $9(52,9 \%)$ & $7(41,2 \%)$ & $0,057 *$ \\
\hline
\end{tabular}




\begin{tabular}{|c|c|c|c|c|}
\hline Consolidação & $1(3,7 \%)$ & $10(37,0 \%)$ & $16(59,3 \%)$ & \\
\hline Diversificação & $0(0,0 \%)$ & $10(37,0 \%)$ & $17(63,0 \%)$ & \\
\hline Renovação & $0(0,0 \%)$ & $4(26,7 \%)$ & $11(73,3 \%)$ & \\
\hline Maturidade & $0(0,0 \%)$ & $3(37,5 \%)$ & $5(62,5 \%)$ & \\
\hline \multicolumn{5}{|c|}{ Geral da Qualidade de vida no trabalho } \\
\hline Entrada & $4(23,5 \%)$ & $5(29,4 \%)$ & $8(47,1 \%)$ & \\
\hline Consolidação & $3(11,1 \%)$ & $12(44,4 \%)$ & $12(44,4 \%)$ & \\
\hline Diversificação & $0(0,00 \%)$ & $16(59,3 \%)$ & $11(40,7 \%)$ & $0,695 *$ \\
\hline Renovação & $1(6,7 \%)$ & $5(33,3 \%)$ & $9(60,0 \%)$ & \\
\hline Maturidade & $1(12,5 \%)$ & $6(75,0 \%)$ & $1(12,5 \%)$ & \\
\hline
\end{tabular}

Na análise geral da QV no trabalho docente, nas dimensões Oportunidade imediata para o uso e Desenvolvimento de capacidades humanas $(73,4 \%)$, Oportunidade futura de crescimento e segurança (42,5\%), Integração social na organização do trabalho $(45,7 \%)$, Constitucionalismo na organização do trabalho $(68,1 \%)$, Espaço total da vida $(37,2 \%)$ e Relevância social da vida no trabalho $(59,6 \%)$, os respondentes demonstraram satisfação, e, na dimensão Remuneração e compensação $(69,1 \%)$, estes sujeitos demonstraram insatisfação. Entretanto, na dimensão Condições de trabalho (35,1\%), os docentes apresentaram o mesmo percentual no que diz respeito à indecisão e insatisfação. Na análise da avaliação geral da QV no trabalho, os professores evidenciaram indecisão (46,8\%), seguidos de valores muito próximos de $(43,6 \%)$ de satisfação. De forma contrária, o estudo de Rosa (2012) realizado com professores do ensino médio demonstrou que os docentes apresentam-se satisfeitos com a sua QV no ambiente de trabalho.

Tabela 5. Avaliação geral da qualidade de vida no trabalho docente

\begin{tabular}{lccc}
\hline \multicolumn{1}{c}{ DIMENSÕES } & $\begin{array}{c}\text { Insatisfeito } \\
\mathbf{n}(\boldsymbol{\%})\end{array}$ & $\begin{array}{c}\text { Indeciso } \\
\mathbf{n ( \% )}\end{array}$ & $\begin{array}{c}\text { Satisfeito } \\
\mathbf{n}(\boldsymbol{\%})\end{array}$ \\
\hline Remuneração e compensação & $65(69,1 \%)$ & $26(27,7 \%)$ & $3(3,2 \%)$ \\
Condições de trabalho & $33(35,1 \%)$ & $33(35,1)$ & $28(29,8 \%)$ \\
Oportunidade imediata para uso e desenvolvimento & $4(4,3 \%)$ & $21(22,3 \%)$ & $69(73,4 \%)$ \\
das capacidades humanas & $18(19,1 \%)$ & $36(38,3 \%)$ & $40(42,5 \%)$ \\
Oportunidade futura de crescimento e segurança & $11(11,7 \%)$ & $40(42,6 \%)$ & $43(45,7 \%)$ \\
Integração social na organização do trabalho & $3(3,2 \%)$ & $27(28,7 \%)$ & $64(68,1 \%)$ \\
Constitucionalismo na organização do trabalho & $31(33,0 \%)$ & $28(29,8 \%)$ & $35(37,2 \%)$ \\
Trabalho e espaço total de vida & $2(2,1 \%)$ & $36(38,3 \%)$ & $56(59,6 \%)$ \\
Relevância social da vida no trabalho & $9(9,6 \%)$ & $44(46,8 \%)$ & $41(43,6 \%)$ \\
Geral da qualidade de vida no trabalho & & &
\end{tabular}

Após análise do estudo, observou-se que os professores vinculados à SMED demonstram altos percentuais de insatisfação com relação à Remuneração em todas as fases da carreira, essa constatação vem ao encontro dos resultados encontrados em diversos estudos (LAPO; 
BUENO, 2000; PETROSKI, 2005; LEMOS, 2007; PENTEADO; PEREIRA, 2007; FOLLE et al., 2008; BOTH; NASCIMENTO; BORGATTO, 2008).

É importante destacar que Remuneração e Compensação, embora tenham surgido como os motivos mais citados, vieram, na maioria dos casos, acompanhadas de outros motivos, relacionados, sobretudo às condições de trabalho, falta de perspectivas de crescimento profissional, além da dificuldade de equilibrar vida profissional e pessoal em função de carga horária elevada (PETROSKI, 2005; LEMOS; NASCIMENTO; BOTH, 2006; PENTEADO; PEREIRA, 2007; LEMOS, 2007). Também foi constatado que, além dos salários, outros fatores ocasionavam insatisfação entre os professores.

Com relação à satisfação, constatou-se elevados índices, nas dimensões Oportunidade imediata para uso e Desenvolvimento das capacidades humanas, Oportunidade futura de crescimento e segurança, Integração social na organização do trabalho, Constitucionalismo na organização do trabalho e Relevância social da vida no trabalho. A satisfação profissional pode ser vista como uma atitude global que passa a ser objeto de estudo no momento que se dá início à valorização do trabalho humano nas instituições considerando um fator que reflete critérios bastante subjetivos.

Neste sentido, considera-se que a QV no trabalho é proveniente da mediação entre o professor e o contexto de intervenção, no qual deverá existir uma relação harmoniosa que suscita a necessidade de vínculos especiais com a escola e com o trabalho docente (LAPO; BUENO, 2003).

\section{Considerações Finais}

O estudo teve como objetivo analisar os aspectos interferentes na QV dos professores de Educação Física da rede pública municipal de Pelotas/RS, considerando, sobretudo, sua satisfação no ambiente de trabalho. Investigar a QV dos professores de Educação Física, merece maior atenção dos pesquisadores, pois este grupo exerce suas atividades laborais em ambiente diferenciado dos demais professores, fato que mesmo mínimo pode gerar desconforto. Desta forma, pode-se destacar que os resultados obtidos permitem avaliar que a maioria dos docentes, apresentou indecisão nas suas afirmações. Por outro lado, grande número de professores mostrou-se satisfeito com a avaliação geral do trabalho, embora estivessem insatisfeitos principalmente na dimensão Remuneração e Compensação.

Os baixos índices de satisfação dos professores nas dimensões Remuneração e Compensação e Condições de trabalho, além de Trabalho e Espaço Total da Vida são preocupantes, pois demonstram a necessidade urgente de melhorias no ensino público municipal. Constatou-se que os resultados encontrados sinalizam para a importância de uma política de apoio à rede municipal, como maneiras de valorizar a carreira docente e prevenir processos destrutivos presentes no mundo do trabalho.

De fato, a análise da QV do docente no decorrer da sua trajetória profissional revela como os professores percebem a sua carreira, sendo coerente afirmar que com o avanço, o que pode ser considerado como insatisfação pode ser alvo de indecisão. $\mathrm{O}$ amadurecimento profissional e o processo de socialização contribuem para o fortalecimento do docente mediado pelo olhar diferenciado sobre as políticas educacionais vigentes. Esta pode ser uma das limitações do estudo, pois investigou somente os docentes de uma única localidade, com uma realidade de planos e cargos que não permite comparação com as demais localizações.

As investigações que abordam QV no trabalho dos professores são excelentes iniciativas para compreender as condições de vida na carreira desse profissional, no entanto existe a necessidade de continuação desses estudos para que os problemas encontrados sejam considerados pelos gestores e pela comunidade escolar, garantindo, assim, um ambiente de trabalho com condições mínimas necessárias para que esse profissional desenvolva seu trabalho da 
melhor forma possível. Sugere-se a utilização de outros instrumentos para pesquisa, bem como uma abordagem com amostra mais ampliada, buscando uma maior representatividade dos dados.

\title{
QUALITY OF LIFE AT WORK: THE CONTEXT OF PROFESSIONAL PRACTICE AND TEACHING CAREER
}

\begin{abstract}
The study aimed to analyze the intervening aspects of quality of life Physical Education teachers considering their satisfaction in the workplace. The study included 94 teachers, linked to SMED pellets. The instruments were the QVT-PEF and demographic questionnaire. Data were analyzed in STATA 12.0 adopting the significance level of 5\%. The highest prevalence of job satisfaction was obtained in the dimension of immediate opportunity to use and development of human capabilities. Already the highest prevalence of dissatisfaction was found in the dimension of remuneration and compensation. Job satisfaction is an important dimension in evaluating the quality of life, but aspects related to the precariousness of the teaching work are negative factors in this context.
\end{abstract}

Keywords: Quality of life. Teachers. Job satisfaction.

\section{CALIDADE DE VIDA EN EL TRABAJO: CARRERA DOCENTE Y CONTEXTO PROFESIONAL}

\section{Resumen}

El objetivo del estudio fue analizar los aspectos que intervienen de calidad de vida de los profesores de Educación Física considerando su satisfacción en su trabajo. Participaron 94 docentes, vinculados a SMED de Pelotas. Los instrumentos fueron el QVT-PEF y el cuestionario demográfico. Los datos fueron analizados en STATA 12.0 adoptando la significación de 5\%. Se obtuvo la más alta prevalencia de la satisfacción en el trabajo en la dimensión de la oportunidad inmediata de uso y desarrollo de las capacidades humanas. Se encontró la mayor prevalencia de la insatisfacción en la dimensión de la remuneración y compensación. Satisfacción en el trabajo es una dimensión importante en la evaluación de la calidad de vida, pero la precariedad de la enseñanza influencia en este contexto.

Palabras-clave: Calidad de vida. Maestros. Satisfacción en el trabajo.

\section{Referências}

BARRETO, R. G.; LEHER, R. Trabalho docente e as reformas neoliberais. In: OLIVEIRA, D. A. (Org.). Reformas educacionais na América Latina e os trabalhadores docentes. Belo Horizonte: Autêntica, p. 39-60, 2003.

BOTH, J.et al. Validade e fidedignidade da escala de avaliação da qualidade de vida no trabalho percebida por professores de Educação Física do ensino fundamental e médio (QVT PEF). Revista Brasileira de Cineantropometria \& Desempenho Humano, Florianópolis, v. 8, n. 2, p. 45-52, 2006.

BOTH, J.; NASCIMENTO, J. V.; BORGATTO, A. F. Percepção da qualidade de vida no trabalho ao longo da carreira docente em Educação Física. Revista Brasileira de Cineantropometria \& Desempenho Humano, Florianópolis, v. 10, n. 4, p. 372-378, 2008. 
BOTH, J. Bem-estar do trabalhador docente em Educação Física. 2011. 297 f. Tese (Doutorado em Educação Física) Centro de Desportos, Universidade Federal de Santa Catarina, Florianópolis, 2011.

CEZAR-VAZ, M. R.; BONOW, C. A.; ALMEIDA, M. C. V.; ROCHA, L. P.; BORGES, A. M. Mental Health of Elementary Schoolteachers in Southern Brazil: Working Conditions and Health Consequences. The Scientific World Journal, Cairo, v. 2015. p. 1-6, 2015.

FARIAS, G. O. et al. Carreira docente em Educação Física: uma abordagem sobre a qualidade de vida no trabalho de professores da rede estadual de ensino do Rio Grande do Sul. Revista da Educação Física/UEM, Maringá, v. 19, n. 1, p. 11-22, 1. Trim. 2008.

FARIAS, G. O. Carreira Docente em Educação Física: uma abordagem na construção da trajetória profissional do professor. 2010. 303f. Tese (Doutorado em Educação Física) - Centro de Desportos, Universidade Federal de santa Catarina, Florianópolis, 2010.

FARIAS, G. O; NASCIMENTO, J. V. Fatores intervenientes na carreira docente de professores de educação física. Pensar a Prática, Goiânia, v. 15, n. 2, p. 465- 483, 2012.

FARIAS, G. O.; NASCIMENTO, J. V. Construção da identidade profissional: metamorfoses na carreira docente em Educação Física. In: NASCIMENTO, J. V.; FARIAS, G. O. (Orgs.). Construção da identidade profissional em Educação Física: da formação á intervenção. Florianópolis: Ed. Da UDESC, 2012. p. 61-79.

FOLLE, A. et al. Carreira no magistério público e nível de qualidade de vida no trabalho docente em Educação Física. Motriz, Rio Claro, v. 14 n. 3, p. 210-221, jul./set. 2008a.

FUESS, V. L. R.; LORENZ, M C. Disfonia em professores do ensino municipal: prevalência e fatores de risco. Revista Brasileira de Otorrinolaringologia, Rio de Janeiro, v. 69, n.6, p. 807-12, nov./dez. 2003

GASPARINI, S. M.; BARRETO, S. M.; ASSUNCAO, A. A. O professor, as condições de trabalho e os efeitos sobre sua saúde. Educação Pesquisa, São Paulo, v. 31, n. 2, Ag. 2005.

GATTI, B. A.; BARRETTO E. S. S.; ANDRÉ M. E. D. A. Políticas docentes no Brasil: um estado da arte. Brasília: UNESCO, 2011.

HUBERMAN, M. O ciclo de vida profissional dos professores. In: NÓVOA, A. (Org.). Vidas de professores. Porto: Porto Editora, 2000. p. 31-61.

LAPO, F. R.; BUENO, B. O. Professores, desencanto com a profissão e abandono do magistério. Cadernos de Pesquisa, Rio de Janeiro, n. 118, p. 66-88, mar. 2003.

LEMOS, C. A. F.; NASCIMENTO, J. V.; BOTH, J. Qualidade de vida no trabalho percebida por professores de educação física. In: FÓRUM INTERNACIONAL INTEGRADO DE CIDADANIA: EDUCAÇÃO, CULTURA, SAÚDE E MEIO AMBIENTE, 2006, Santo Ângelo - RS. Anais... Santo Ấngelo-RS, 2006, v. 1, p. 68-88.

LEMOS, C. A. F. Qualidade de vida na carreira profissional de professores de Educação Física do magistério público estadual/RS. 2007. 114 f. Dissertação (Mestrado em Educação Física) - Centro de Desportos, Universidade Federal de Santa Catarina, Florianópolis, 2007. 
LEMOS, C. L. A. F.; NASCIMENTO, J. V.; BORGATTO, A. F. Parâmetros individuais e sócio-ambientais da qualidade de vida percebida na carreira docente em Educação Física, Revista Brasileira de Educação Física e Esporte, São Paulo, v. 21, n. 2, p. 81-93, 2007.

MARTINEZ, M. C.; PARAGUAY, A. I. B. B. Satisfação e saúde no trabalho - aspectos conceituais e metodológicos. Cadernos de Psicologia Social do Trabalho, vol. 6, p. 59-78, 2003.

MOREIRA, H. R.; FARIAS, G. O.; BOTH, J.; NASCIMENTO, J, V. Qualidade de vida no trabalho e Síndrome de Burnout em professores de Educação Física do estado do Rio Grande do Sul, Brasil. revista Brasileira de Atividade Física \& Saúde, Pelotas, v. 14, n. 2, p. 115-122, 2009.

NAHAS, M. V.; BARROS, M. G. V.; FRANCALACI, V. O. Pentáculo do Bem-Estar: base conceitual para a avaliação do estilo de vida em indivíduos ou grupos. Revista Brasileira de Atividade Física e Saúde, Pelotas, p.48-59, 2000.

NAHAS, M. V. Atividade física, saúde e qualidade de vida: conceitos e sugestões para um estilo de vida ativo. Londrina: Midiograf, 2010.

OLIVEIRA, D. A. As reformas educacionais na América Latina e os trabalhadores docentes. Belo Horizonte: Autêntica, 2003.

PENTEADO, R. Z.; PEREIRA, I. M. T. B. Qualidade de vida e saúde vocal de professores. Revista de Saúde Pública, São Paulo, v. 41, n. 2, Abr. 2007

PETROSKI, E. C. Qualidade de vida no trabalho e suas relações com estresse, nível de atividade física e risco coronariano de professores universitários.2005. 163f. Dissertação (Doutorado em Engenharia de Produção) - Centro Tecnológico, Universidade Federal de Santa Catarina, Florianópolis, 2005.

ROSA, S. J. A qualidade de vida no trabalho dos professores do ensino médio da educação básica pública e privada de Paracatu - M.G. 2012. 100f. Dissertação (Mestrado Profissional em Administração) - Faculdades Integradas de Pedro Leopoldo, Pedro Leopoldo, 2012.

SOUZA, K. R. et al. Trajetória do Sindicato Estadual dos Profissionais da Educação do Rio de Janeiro (SEPE-RJ) na luta pela saúde no trabalho. Ciência \& Saúde Coletiva, Rio de Janeiro, v. 8, n. 4, p. 1057-1068, 2003.

THOMAS, J. R.; NELSON, J. K. Métodos de pesquisa em atividade física. Porto Alegre: Artmed, 2002.

VASCONCELOS, A. F. Qualidade de vida no trabalho: origem, evolução e perspectivas. Caderno de pesquisas em Administração, São Paulo,_ v.8, n.1, p. 23-35, 2001.

VIEIRA, A. S. et al. As condições de trabalho do professor e os seus efeitos sobre sua saúde. In: X NACIONAL DE EDUCAÇÃO (EDUCERE), I SEMINÁRIO INTERNACIONAL DE REPRESENTAÇÕES SOCIAIS, SUBJETIVIDADE E EDUCAÇÃO (SIRSSE), 2011, Curitiba. Anais... Curitiba: EDIPUC, 2011. p. 2471-2481. 
Recebido em: 21/07/2015

Revisado em: 29/10/2015

Aprovado em: 10/05/2017

Endereço para correspondência:

zeantonio_bicca@hotmail.com

José Antonio Bicca Ribeiro

Universidade Federal de Pelotas

R. Gomes Carneiro, 1 - Centro, Pelotas - RS

96010-610 